\title{
Schamberg's disease: case report with therapeutic success by using colchicine*
}

\author{
Maria Lopes Lamenha Lins Cavalcante ${ }^{1}$ \\ Fernanda Freitas de Brito ${ }^{1}$ \\ Gabriela Itimura $^{1}$
}

\author{
Paula Yoshiko Masuda ${ }^{1}$ \\ Ana Cecília Versiani Duarte Pinto ${ }^{1}$ \\ Adauto José Ferreira Nunes ${ }^{1}$
}

DOI: http:/ / dx.doi.org/10.1590/abd1806-4841.20174898

\begin{abstract}
Pigmented purpuric dermatoses (PPD) include a spectrum of diseases with different clinical aspects, but with similar histopathological features. Specific clinical findings allow the division of PPD in variants. Schamberg's disease is the most common. Treatment is sometimes ineffective and recurrences are common. There are reports of patients who responded well to the use of colchicine. We report the case of a 32-year-old woman, previously healthy, with a history of onset of asymptomatic lesions in legs. She presented purpuric skin eruptions and brownish stains diffusely distributed in the lower limbs. Biopsy was compatible with PPD. We decided for the introduction of colchicine, with good clinical response. The patient has been followed on outpatient basis for ten months without recurrence.
\end{abstract}

Keywords: Colchicine; Purpura; Therapeutics; Pigmentation disorders

\section{INTRODUCTION}

Pigmented purpuric dermatoses (PPD) include a spectrum of vascular diseases, usually of unclear etiology, various clinical aspects, but with some common histopathological features such as red blood cells extravasation, hemosiderin deposition (mainly within the dermal macrophages), narrowing of small vessel lumen, endothelial edema and lymphocytic perivascular infiltrate. ${ }^{1}$ They occur predominantly in the lower limbs of adults, but can affect children. Some particular clinical aspects allow the division of PPD into eponymous variants: Schamberg's disease, pigmented purpuric lichenoid dermatitis of Gougerot-Blum, purpura annularis telangiectodes of Majocchi, eczematid-like purpura of Doucas and Kapetanakis and lichen aureus. ${ }^{2}$ Treatment is sometimes ineffective, and recurrences are not uncommon. The use of skin emollients and moisturizers is often employed. Variable results can be obtained with pentoxifylline, griseofulvin, oral corticosteroids, topical corticosteroids and PUVA. Oral rutoside and vitamin C improved some patients after four weeks. ${ }^{3}$ There are reports in the literature of patients who had a good response to the use of colchicine after six months of treatment. ${ }^{4,5}$

\section{CASE REPORT}

A 32-year-old woman, Caucasian, healthy patient, reported onset of asymptomatic red lesions in the lower limbs with three months of evolution. She denied infection or use of any medication preceding the cutaneous picture, as well as similar cases in the family. The patient reported that, during this period, the lesions increased in number, with caudal-cranial evolution. She referred appearance of new lesions succeeding the old ones, which slowly presented bleaching. She used topical dexamethasone and oral vitamin $C$ for one month, without improvement. At the dermatological examination, there were several purpuric lesions $(1$ to $2 \mathrm{~cm}$ in diameter), some erythematous-violaceous and brownish lesions with residual aspect diffusely distributed in the lower limbs (Figure 1) and lower abdomen. Diascopy was negative. The diagnostic hypothesis of Schamberg's disease was confirmed by clinical findings and corroborated by biopsy showing discrete epithelial hyperplasia, occasional foci of spongiosis, and superficial lymphohistiocytic infiltrate, predominantly perivascular, with red blood extravasation (Figure 2). Colchicine $0.5 \mathrm{mg}$ twice daily was introduced. The patient returned after two months, reporting a significant improvement of

Received on 01.07.2015

Approved by the Advisory Board and accepted for publication on 13.01.2016

* Study conducted at the Instituto Lauro de Souza Lima (ILSL) - Bauru (SP), Brazil.

Financial support: none.

Conflict of interest: none.

1 Department of Dermatology of the Instituto Lauro de Souza Lima (ILSL) - Bauru (SP), Brazil.

(C2017 by Anais Brasileiros de Dermatologia 

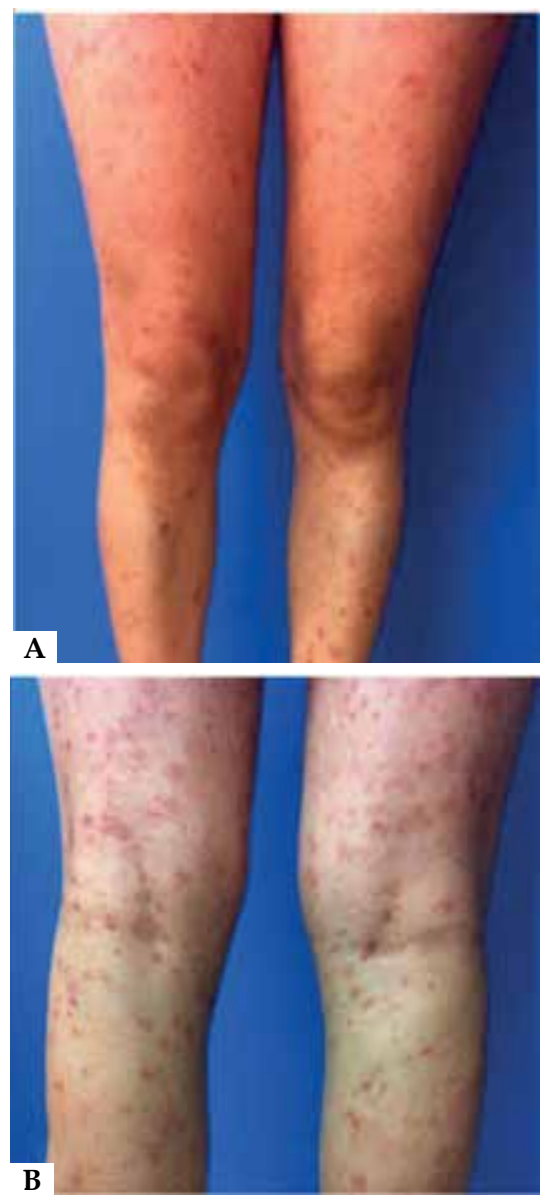

Figure 1: A. Purpuric lesions, 1 to $2 \mathrm{~cm}$ in diameter, some erythematous-violaceous and brownish macules with residual appearance diffusely distributed in lower limbs (anterior view, on admission); B. Purpuric lesions, 1 to $2 \mathrm{~cm}$ in diameter, some erythematous-violaceous and brownish lesions with residual appearance diffusely distributed in lower limbs (posterior view, on admission)

the lesions, without new ones. After four months of treatment, she presented complete regression (Figure 3). She was followed for ten months without any medication, and there was no recurrence of the lesions.

\section{DISCUSSION}

Schamberg's disease, also called progressive pigmented purpuric dermatitis, is the most common PPD. It predominantly affects men at any age. ${ }^{2}$ Medications are the triggering factors most frequently related to PPDs, especially in Schamberg's disease, among them paracetamol and acetylsalicylic acid. ${ }^{3}$ The patient in this report denied the use of any medication, even sporadically. The lesions initially occur in the lower limbs, but may arise in any area of the body. Hemosiderin deposits arise within and on the margins of older lesions, giving the classic appearance of cayenne pepper stains. The disease has a chronic course, with new lesions succeeding the old ones that slowly present bleaching. There may be ascending lesions in the caudal-cranial direction. ${ }^{2}$ All these characteristics were found in the patient and allowed clinical suspicion, which was confirmed by anatomopathological examination. Schamberg's disease
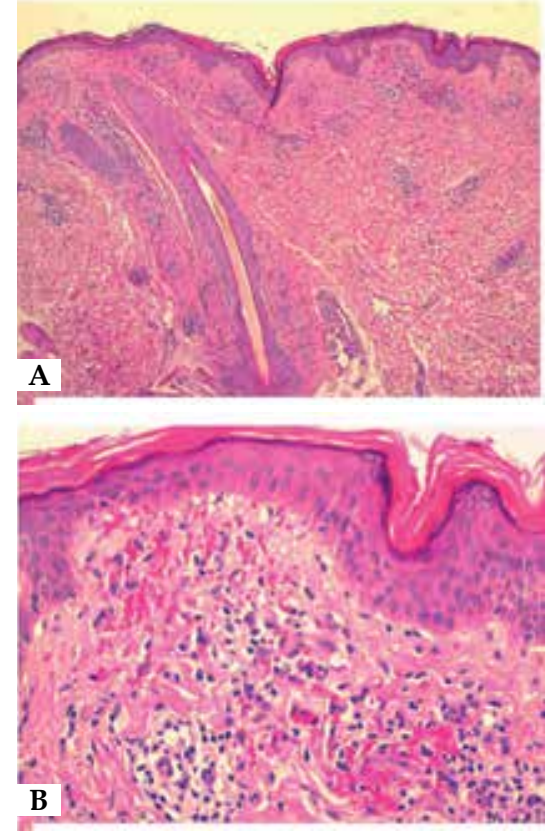

Figure 2: A. HE 40x: Skin with mild epithelial hyperplasia, occasional foci of spongiosis, and predominantly perivascular superficial lymphohistiocytic infiltrate with extravasation of red blood cells; B. HE 200x: Detail of superficial lymphohistiocytic infiltrate with extravasation of red blood cells
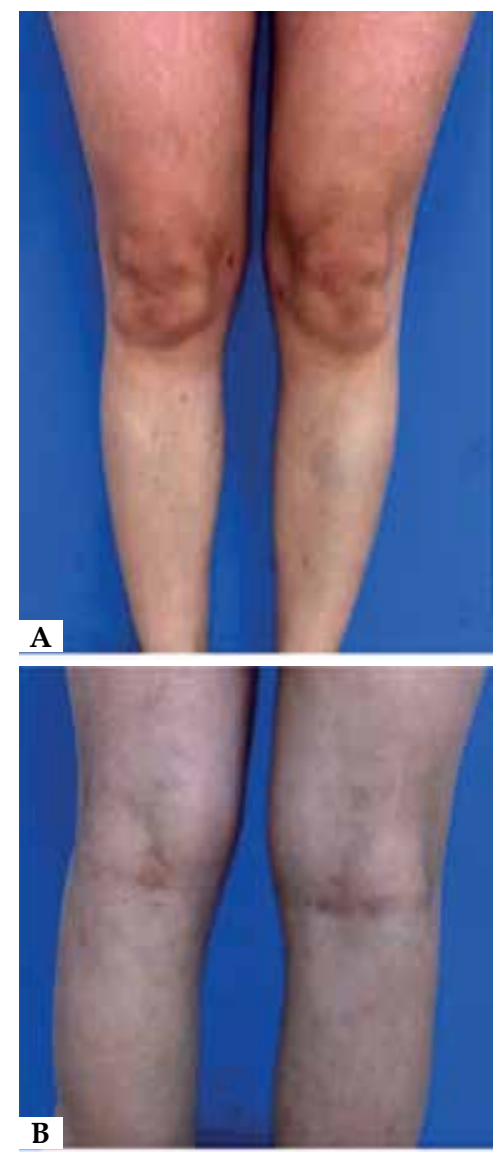

Figure 3: A. Absence of lesions after four months of treatment with colchicine (anterior view); B. Absence of lesions after four months of treatment with colchicine (posterior view) 
is still considered idiopathic, without an established therapy. To date, there is no effective treatment, but there is general agreement regarding the use of anti-inflammatory drugs to treat skin diseases with immune mediation. ${ }^{3}$ The first report of the benefit of colchicine in the control of Schamberg's disease dates back to 2000, and in 2004 another case was reported by the same author.$^{4,5}$ The presentation of this case contributes to demonstrate the use of colchicine as a lowcost, short-term therapeutic option with no adverse events reported by the patient, in addition to preventing relapses. $\left.{ }^{4}\right]$

\section{REFERENCES}

1. Gönül M, Külcü Çakmak S, Ozcan N, Oğuz ID, Gül U, Bıyıkı Z. Clinical and laboratory findings of pigmented purpuric dermatoses. Ann Dermatol. 2014;26:610-4.

2. Sharma L, Gupta S. Clinicoepidemiological study of pigmented purpuric dermatoses. Indian Dermatol Online J. 2012;3:17-20.

3. Sardana K, Sarkar R, Sehgal VN. Pigmented purpuric dermatoses: an overview. Int J Dermatol. 2004;43:482-8.

4. Geller, M. Novo tratamento bem-sucedido da púrpura de Schamberg com colchicina. Einstein. 2004; 2: 2067.

5. Geller M. Benefit of colchicine in the treatment of Schamberg's disease. Ann Allergy Asthma Immunol. 2000;85:246.
MAILING ADDRESS:

Maria Lopes Lamenha Lins Cavalcante

Rodovia Comandante João Ribeiro de Barros, km 225/226

17039-800 - Bauru - SP

Brazil

Email: maria.lamenha@gmail.com

How to cite this article: Cavalcante MLLL, Masuda PY, Brito FF, Pinto ACVD, Itimura G, Nunes AJF. Schamberg's disease: case report with therapeutic success by using colchicine. An Bras Dermatol. 2017;92(2):246-8. 